\title{
Potential ecotoxicity impact induced by plant protection products in Finnish crop farming
}

\author{
K. Räsänen ${ }^{1}$, T. Mattila², P. Porvari², S. Kurppa1', K. Tiilikkala1 \\ ${ }^{1}$ MTT Agrifood Research Finland, ${ }^{2}$ Finnish Environment Institute SYKE
}

\section{Introduction}

-Potential ecotoxicity impact in LCA approach was used as an indicator for studying environmental effects of plant protection products (PPPs) in Finland.

\section{How ecotoxicity is forming in LCA ? - Figures 1 and 2}

- Chemicals' ecotoxic effects can be measured with the ecotoxicity impact assessment in LCA per functional unit of the final product

- Chemicals are used in different steps of the product chain, e.g. PPPs in the crop production in a field or industrial chemicals in the production of food packing materials

$\approx$ ecotoxicity footprint

\section{Material and methods}

How ecotoxic effects induced by PPP usage were measured?

-PestLCI 2.0 (Dijkman et al. 2012) was used to model emission fate assuming average Finnish field conditions -SETAC consensus LCIA model USEtox ${ }^{\mathrm{TM}}$ (version 1.01) (Rosenbaum et al. 2008, Usetox ${ }^{\mathrm{TM}}$ 2013) were used to calculate characterization factors. The model was customized to fit Finnish regional environmental conditions by obtaining the relevant parameters from GIS.

$\rightarrow$ a potential ecotoxic pressure (= impact score, CTU as an unit) describes the potentially affected fraction of species in the environment induced by the usage a PPP

-values were calculated for 64 compounds from over 220 different applications

PPP sale data (active ingredient kg/year) was surveyed by Finnish Chemical Agency (Tukes) over the years 2000-2011.

-In Finland

- herbicides were the most used agricultural PPPs from the total 1707.5 tons

PPPs were used $0.7 \mathrm{~kg} / \mathrm{ha}$ in the total agricultural land in 2011

\section{Results}

Figure 3. Overall ecotoxic pressure decreased over the time scale mainly because decreased sale amount of the main hazardous substance fluazinam.

$$
\text { Single very hazardous substances had a strong increasing effect on the total impact. }
$$

There was no correlation between sales amount and ecotoxic pressure (R2=0.0007).

Figure 4. The main contributors to the total potential ecotoxic impact were fungicides.

- Figure 5. The most hazardous substances were fluazinam, aclonifen, methiocarb, pendimethalin and prochloraz.

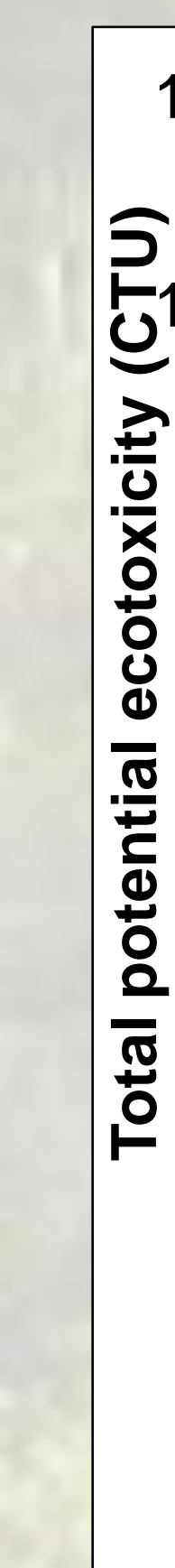

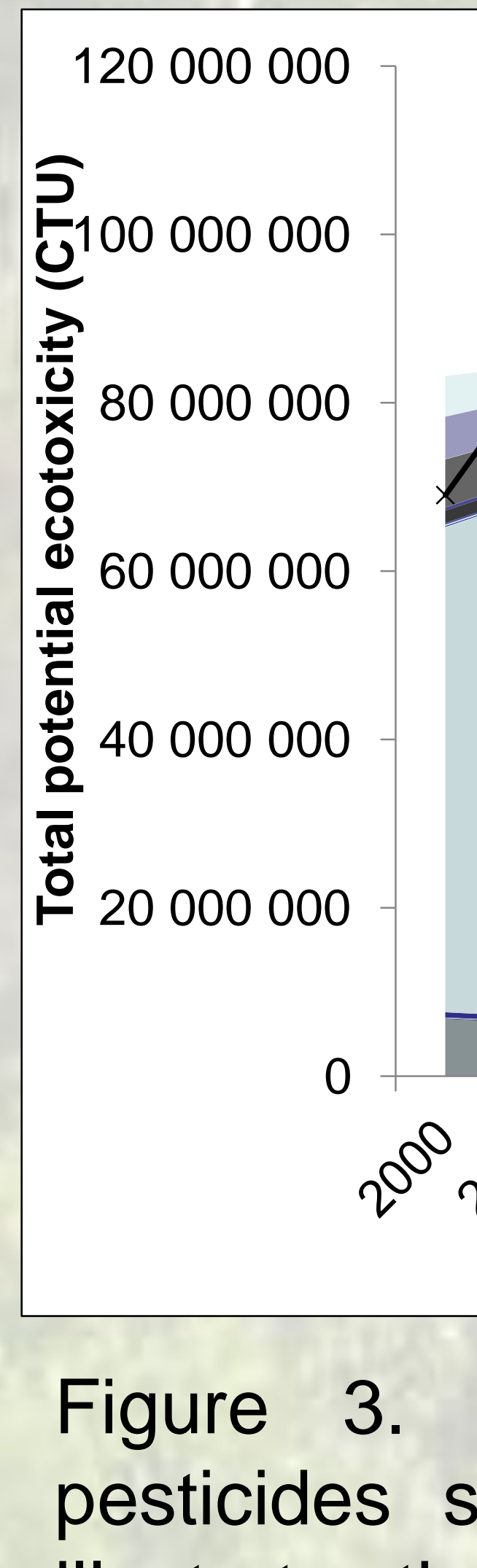
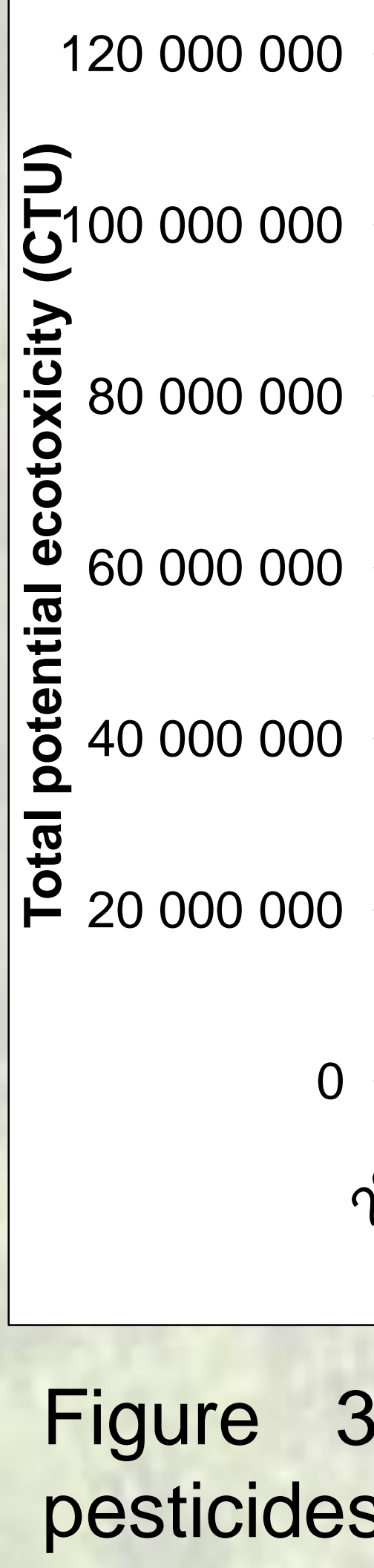

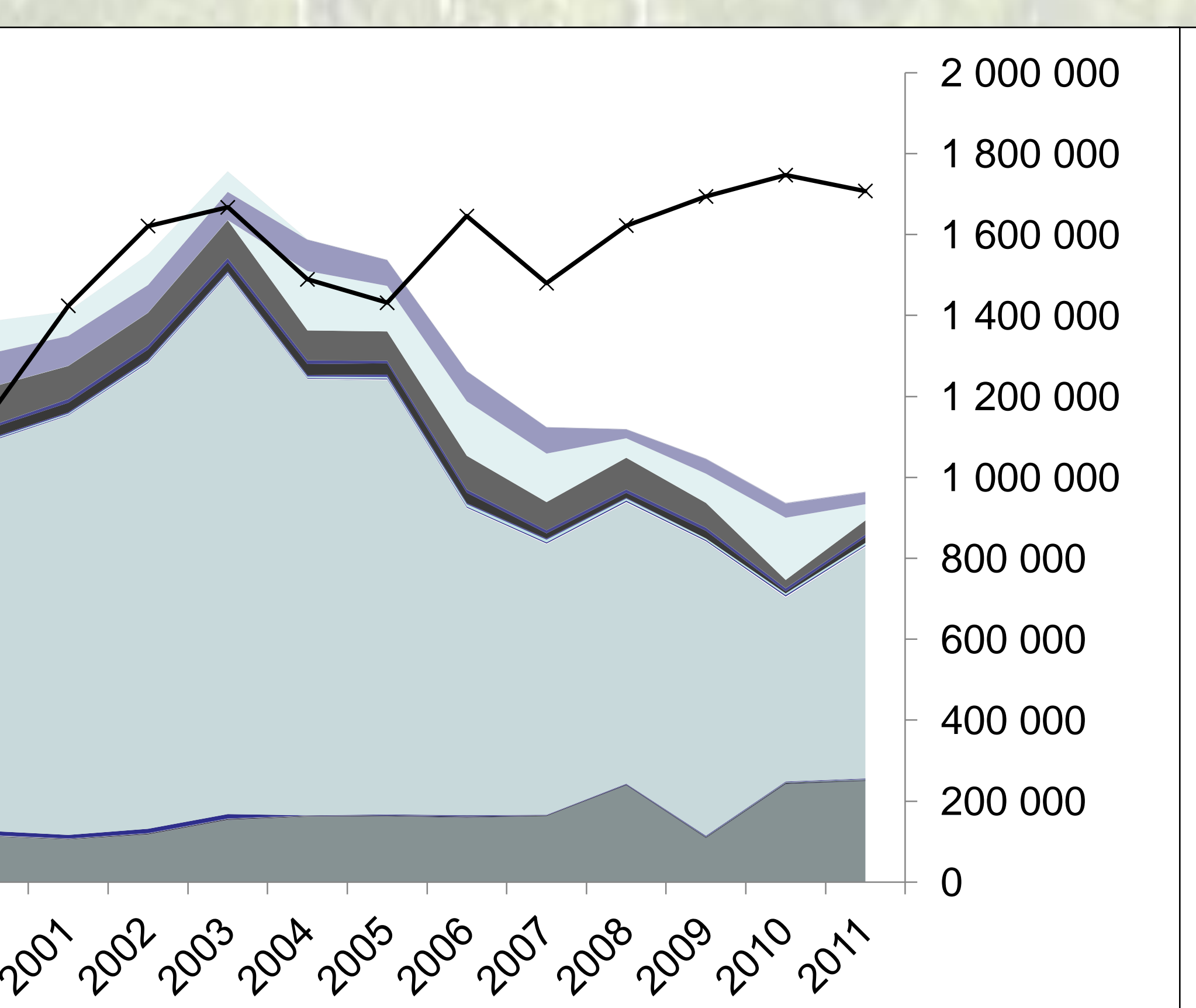
Year of PPP sale

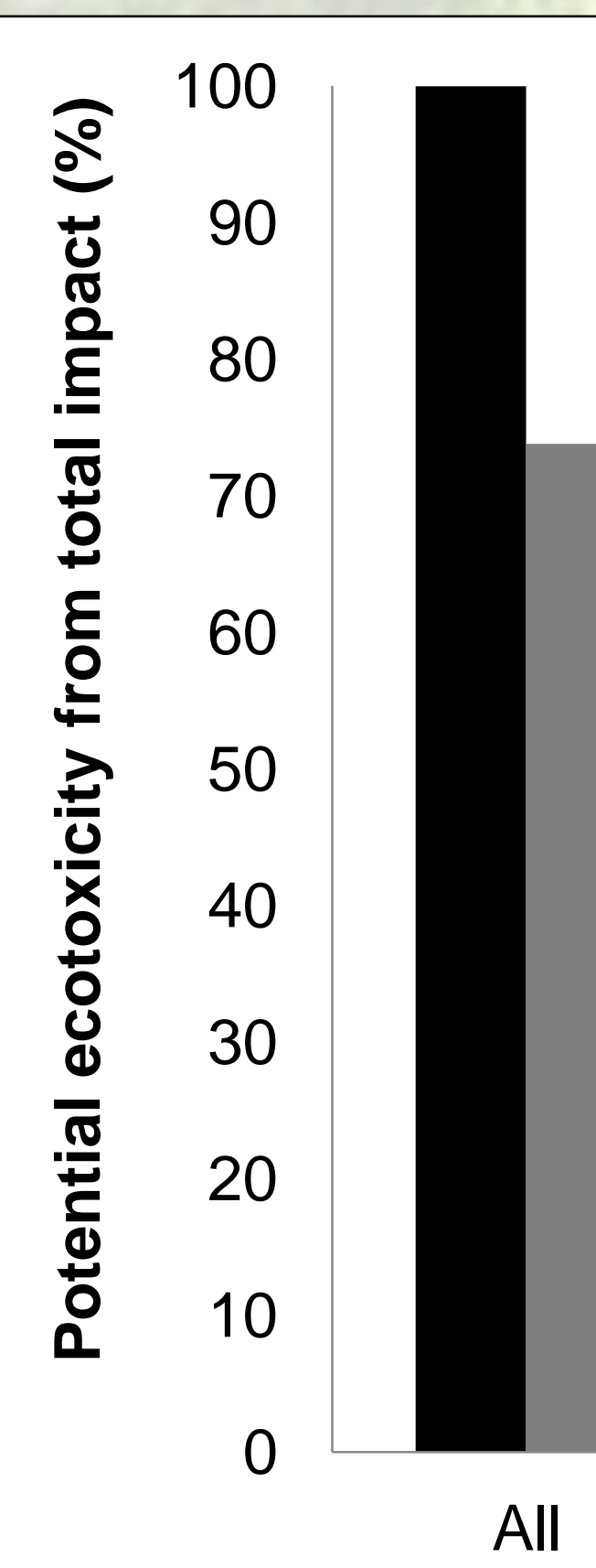

All

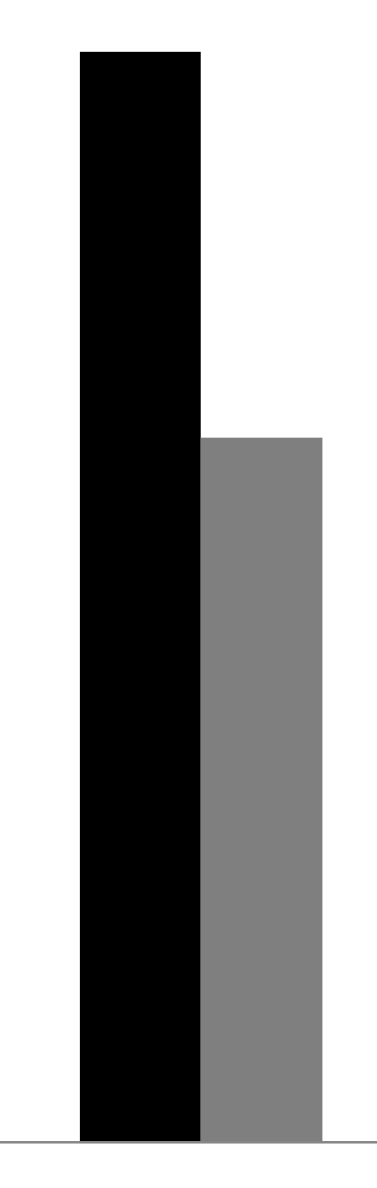

Fungicides

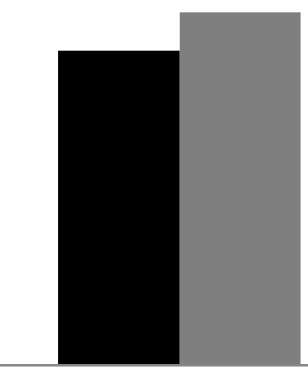

Herbicides

Gactors

Figure 4. PPP substance groups in order to affect ecotoxicity pressure (in CTUs). Values are sum of average impacts per year of active ingredients in substance groups over 2000-2011 in Finland (\%).

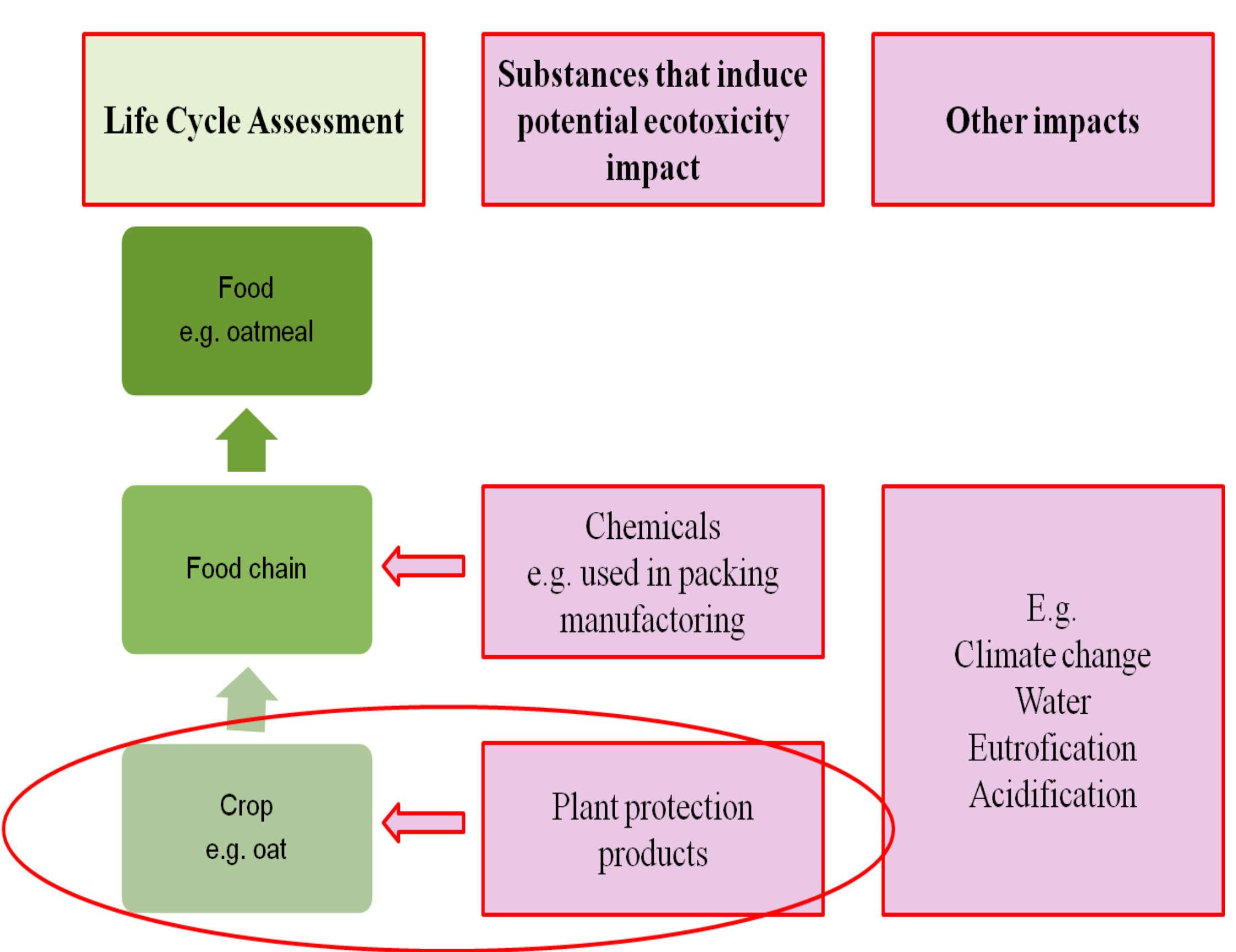

Figure 1. Forming of potential ecotoxicity in LCA. Circle illustrates the scope of our study.

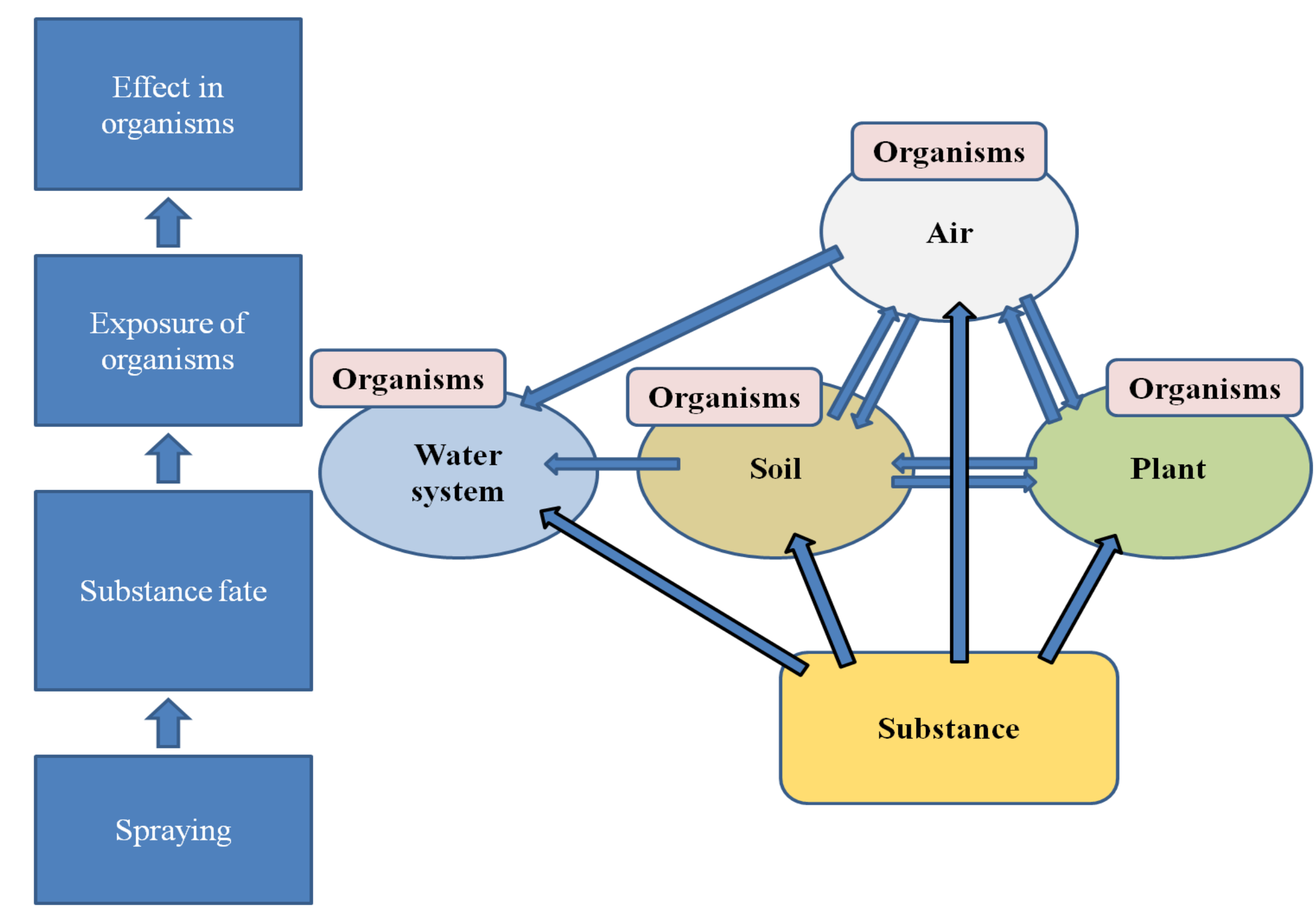

Figure 2. The potential ecotoxic impacts of PPP emissions can be evaluated in LCA by modelling the fate of active ingredient in air, water, and soil and their exposure and effects on organisms. PestLCl and Usetox were used in our studies.

\section{Conclusions}

-With this method the effects of high amount of different chemicals used in specific geographical condition can be compared to each others.

-> changes can be done in risk evaluations and management nationally e.g. to exclude the most hazardous substances from the sales and replace them safer ones or to change methods in the agriculture towards to more environmental friendly way

$\rightarrow$ results can be used in product chain improvements or consumer communication

- The risk results are also recommended to be related to the quantity and quality of the yield for obtaining the benefits from using of plant protection products - Other LCA impact categories and methods linked to crop production should also be evaluated for obtaining more realistic environmental effects in the agricultural field system. 